\title{
METAL ALLOYS FOR FILAMENTS IN 3D FUSION FILAMENT MODELLING PRINTING PROCESS
}

\author{
M. Ciornei1, I. D. Savu ${ }^{*}$, S. V. Savu ${ }^{2}$ \\ ${ }^{1}$ Territorial Labour Inspectorate of Mehedinti, 3 Carol I St., 220099, Drobeta Turnu-Severin, Romania \\ ${ }^{2}$ University of Craiova, Faculty of Mechanics, 1 Calugareni St., 220037, Drobeta Turnu-Severin, Romania \\ *Corresponding author's e-mail address: danut.savu@ymail.com
}

\begin{abstract}
The paper presents experimental research regarding the application of specific low melting metals in the FDM process. Previous trends in the transfer of the filament from the spool to the hot-end showed that the filament undergoes specific mechanical stress during the transfer. To achieve an appropriate transfer the filament should prove stiffness and resistance to the mechanical actions of the transfer wheels. At the same time, the entrance to the hot-end creates specific resistance to the movement of the filament, and the filament undergoes important deformations. The experimental research used three materials characterized by melting temperature below $260^{\circ} \mathrm{C}$ : Sn-58Bi, Sn-9Zn, and Sn-3.5Ag. Sn-58Bi showed a yield stress above $50 \mathrm{MPa}$, but very low extension during the tensile test. Sn-9Zn exhibited a yield stress above $30 \mathrm{MPa}$, and about double the extension during the tensile test. Sn-3.5Ag displayed a yield stress above $25 \mathrm{MPa}$, and extension in excess of $8 \%$. The analysis of the surface was performed, revealing that the increase of the yield stress influenced the appearance of specific prints given by the transfer wheels. The deepest prints were measured for Sn-3.5Ag and they were maximum $100 \mu \mathrm{m}$. The other two materials were stiffer and the prints have depths below $50 \mu \mathrm{m}$. According to the obtained results, each of the tested materials can be an appropriate solution to filament use for the FDM $3 D$ printing process.
\end{abstract}

KEYWORDS: FDM printing process, low fusion metals, mechanical characteristics, transfer of metal filament, deformation of filament.

\section{INTRODUCTION}

3D printing through the FDM process is a smart technology of additive manufacturing [1]-[9]. It consists in building a three-dimensional solid object having a highly complex shape, performed by a continuous process of depositing successive layers of polymers [1], [2], [8], [9]-[11]. By its principle, this technology is distinct from traditional processing technologies, which are mainly based on the removal of materials by methods such as cutting, which is a subtractive process [2], [4], [9].

In recent years, the results of a much research have been presented on 3D printing, in general, and FDM printing, in particular [1]-[9]. Shabrubudin and colab. [1] and Mahamood [9] and Turner [13] analysed the influences of the printing process on the printed products, for different printing processes. They presented the main factors in need of control in order to obtain improved to optimal quality printed products. Ciornei [2], [4] analysed the new changes brought about by additive manufacturing in point of costs and manufacturing safety. Polymers used for filament were studied by Shabrubudin and colab. [1], Berger [5], Finnes [6], Savu [7] and Melnikova [8], to evaluate their performances during and after the printing process. Turner [10] and Durgun [11] studied the influences of each parameter on the characteristics of the product. Similar research was performed by Shabat [12] who analysed the mechanical performances of the products printed by using the ABS polymer. Li [13] tried to improve the mechanical properties of the deposited polymer by adding a second source of energy, which was ultrasonic vibration. Rosenthal [14] analysed the propagation of the cracks in a specific product, which is an application of the additive manufacturing in medicine. A general view over the potential of the additive manufacturing in prototyping was presented by Go [15]. Taking into account all the results of these researchers, better control of the process was obtained in time for all additive manufacturing processes and for FDM process in particular. The main printer manufacturers have continuously optimized specific structural elements of the existing printers and new printers have been developed. 
Because of the low printing temperature of polymers used in the FDM process $\left(160 \ldots 280^{\circ} \mathrm{C}\right)$, none of the identified reports refers to another type of material for filaments. Applying the FDM process to create printed products, which are designed to have appropriate function if built of polymers, then the use of polymers for the prototypes is considered acceptable [3]-[5].

When using the FDM process to build a prototype of a product which requires metallic structure and characteristics, the use of polymers for the prototype involves errors when passing from the prototype to the real product, from the functionality point of view. Such products are specific washers with complex sections, soft metal sealing rings, small fittings, electrical connection elements, elements for low power relays, and many others. On these grounds, it is important to start discussing the possibility to develop a version of the FDM process, which is able to use metals instead of polymers. The paper presents several preliminary results of experimental research which aims to evaluate the possibility of using low fusion metals for the filaments dedicated to the FDM process.

\section{LOW FUSION ALLOYS}

Starting with the applications from the electronic industry, where the solders have a melting point below $240^{\circ} \mathrm{C}$, [16]-[20], the authors propose to evaluate the possibility of using the alloys specific to solders.

Table 1. Low fusion alloys dedicated to soldering in electronics [10]

\begin{tabular}{|c|c|}
\hline Alloy & Melting Range $\left[{ }^{\circ} \mathrm{C}\right]$ \\
\hline \multicolumn{2}{|c|}{$\begin{array}{l}\text { Sn }+ \text { single alloying element } \\
(\mathrm{Bi}, \mathrm{Zn}, \mathrm{Ag}, \mathrm{Cu}, \mathrm{Sb}, \text { mainly) }\end{array}$} \\
\hline $\mathrm{Sn}-58 \mathrm{Bi}$ & 139 \\
\hline $\mathrm{Sn}-9 \mathrm{Zn}$ & 198.5 \\
\hline Sn96.3Ag3.7 & $221-229$ \\
\hline Sn95Ag5 & $221-245$ \\
\hline Sn97Ag3 & $221-224$ \\
\hline Sn96.5Ag3.5 & 221 \\
\hline $\mathrm{Sn} 99.3 \mathrm{Cu} 0.7$ & 227 \\
\hline Sn95Sb5 & $232-240$ \\
\hline \multicolumn{2}{|c|}{$\begin{array}{l}\text { Sn }+ \text { two alloying elements } \\
\text { (Ag and } \mathrm{Cu} \text {, mainly) }\end{array}$} \\
\hline Sn95.5Ag4Cu0.5 & 217 \\
\hline Sn95.5Ag3.8Cu0.7 & 217 \\
\hline $\mathrm{Sn} 96.5 \mathrm{Ag} 3 \mathrm{Cu} 0.5$ & $217-220$ \\
\hline Sn99Ag0.3Cu0.7 & $217-228$ \\
\hline \multicolumn{2}{|c|}{$\begin{array}{l}\text { Sn }+ \text { three alloying elements } \\
\text { (Ag and } \mathrm{Sb} \text { and } \mathrm{Cu} \text {, mainly) }\end{array}$} \\
\hline $\begin{array}{l}\text { Sn97Ag0.2Sb0.8Cu2 } \\
\ldots\end{array}$ & $220-234$ \\
\hline
\end{tabular}

In 2002 the 2002/95/EC EU Directive "Restriction of Hazardous Substances Directive (RoHS)" was published, introducing restrictions in using lead as alloying element for solders. Since then, research was performed in order to develop new families of solders, in which indium, or bismuth, or silver, or other low fusion element could replace lead within the chemical composition of the solder. As a result, families of solders appeared, containing eutectics of different alloying system, as $\mathrm{Sn}-\mathrm{Ag}, \mathrm{Sn}-\mathrm{Ag}-\mathrm{Cu}, \mathrm{Sn}-\mathrm{Bi}, \mathrm{Sn}-\mathrm{In}$, and many others which have eutectics with the fusion point below $240^{\circ} \mathrm{C}$ [18]. Table 1 shows the commonly used alloys having fusion points below $240^{\circ} \mathrm{C}$, according to the Kester Alloy Chart.

\section{FUNCTIONING CONDITIONS FOR THE FILAMENT}

During the printing process the filament is transferred from a spool to the hot-end where it is melted and deposited. The transfer is carried out at a constant speed of the filament for the entire time of the process. To provide an appropriate transfer of the filament it is necessary to analyse the mechanical stress of the filament during the transfer process. When using wheels for the transfer of a filament, which have a smooth and low roughness surface, a proper dosing of the contact force between the wheels and the filament should be set, in order to prevent the filament from slipping between the transfer rollers. At the same time, on increasing the contact force, the deformation of the filament, from circular to oval section, could occur. Due to this potential deformation of the filament, it is considered that the transfer requires specific stiffness of the filament, which should be assured even if the filament diameter is small (usually $1.75 \mathrm{~mm}$ ). The stiffness is necessary for two reasons: to avoid the deformation of the circular section of the filament by the transferring wheels (Fig. 1), and to avoid the deformation of the filament segment included between the exit point from the rolling system of wheels and the entrance into the hot-end (Fig. 2).

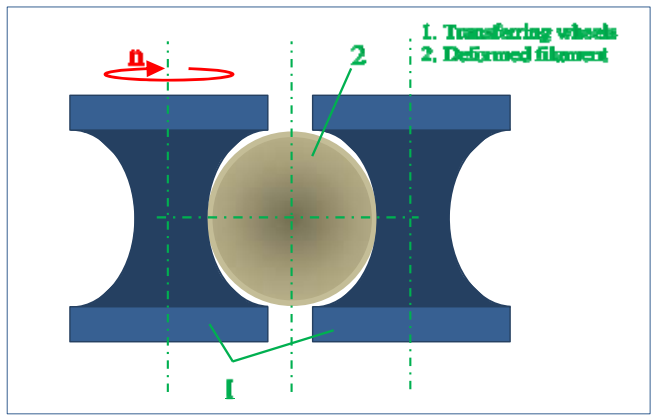

Fig. 1. Deformation of the circular section of filament (sketch) 


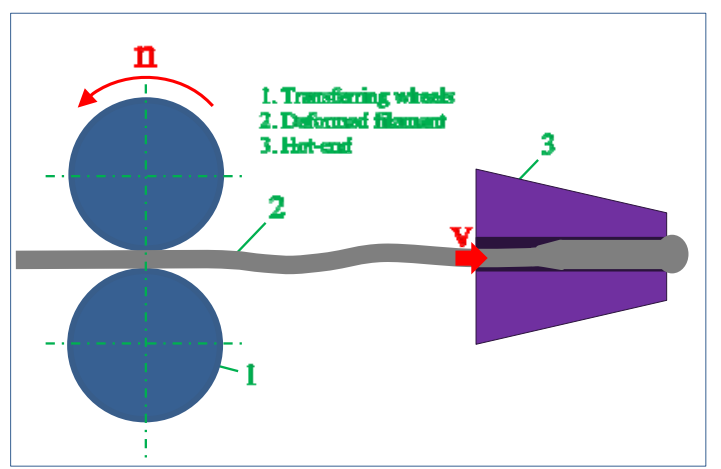

Fig. 2. Deformation of the wire section between pushing wheels and resistant hot-end (sketch)

Most of the low fusion metals are known as soft materials [10-13] and the required stiffness, that the filament should have, is possible not to be reached by all these materials. For this reason, it is necessary to investigate their mechanical characteristics. If the yield strength is higher than the stress produced during the transfer, then the filament will display appropriate behaviour. If not, the filament will get deformed and the transfer will be blocked.

The stress that is developed inside the filament can be calculated beforehand taking into account the transfer system structure. Usually, the structures of the main commercial $3 \mathrm{D}$ printers contain step by step motors. They have mechanical torques within the range of 2.2-12.0 N.m. If specific gears are used, the torque could rise to maximum double, i.e. $24 \mathrm{~N} \cdot \mathrm{m}$.

In that case the filament has to have sufficient strength in order not to be deformed by the pushing process aiming to ensure the transfer. For $10 \mathrm{~mm}$ diameter transfer wheels (Fig. 3) a force of around 5 $\mathrm{N}$ is obtained, which pushes the filament to the hotend.

Most of the printers use filaments $1.75 \mathrm{~mm}$ in diameter. That means that they have a transverse section around the value of $2.4 \mathrm{~mm}^{2}$. Taking into account the $5 \mathrm{~N}$ applied pushing force, a basic stress of $2.08 \mathrm{MPa}$ is expected to be developed within the filament's material. In conclusion it is necessary that the filament's material should be characterized by a yield stress which has a value above the calculated stress of $2.08 \mathrm{MPa}$.

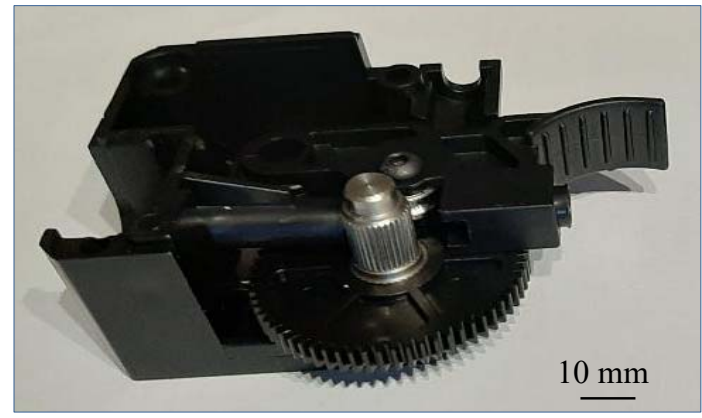

Fig. 3. Transferring wheels used to experimental
From the large number of solders, three were selected to be subjected to mechanical testing, in order to evaluate their functional characteristics, in conditions specific to the work of filaments. The criteria used for the selection process were: melting temperature below $260^{\circ} \mathrm{C}$ (which is the temperature for the $3 \mathrm{D}$ printing by FDM process using PLA filament) and a lower price than the average price of commercial solders. The chosen low fusion alloys are eutectics or neareutectics of the systems $\mathrm{Sn}-\mathrm{Bi}, \mathrm{Sn}-\mathrm{Zn}$ and $\mathrm{Sn}-\mathrm{Ag}$. Each of them has a low price and possesses a melting temperature of below $260^{\circ} \mathrm{C}$.

The first low fusion alloy was $\mathrm{Sn}-58 \mathrm{Bi}$ having the lowest melting temperature, which is $139^{\circ} \mathrm{C}$, [13]. Of the $\mathrm{Sn}-\mathrm{Zn}$ system, the alloy $\mathrm{Sn}-9 \mathrm{Zn}$ was chosen, with the melting point at $198.5^{\circ} \mathrm{C},[13]$. The third tested alloy is $\mathrm{Sn}-3.5 \mathrm{Ag}\left(221^{\circ} \mathrm{C}\right.$, [13]), one of the most commonly used alloys for solders.

\section{EXPERIMENTAL STUDY}

As specified above, the tensile test was applied to the $\mathrm{Sn}-58 \mathrm{Bi}$, and $\mathrm{Sn}-9 \mathrm{Zn}$, and $\mathrm{Sn}-3.5 \mathrm{Ag}$ specimens, to reveal their elastic domain. First, the direct test was applied on the specimen consisting of real filament (Fig. 4a). Such a test was expected to provide the most relevant information, but the test failed due to the high softness of the material that produced extreme deformation of the specimen within the grips of the testing machine. The material underwent breakage at the edge of the fixing grips (Fig. 4b), even if the pulling force was low in value (Fig. 5). The information obtained was not valid when using the filament as specimen for testing, because the testing machine was not able to provide an error-free yield strength value.

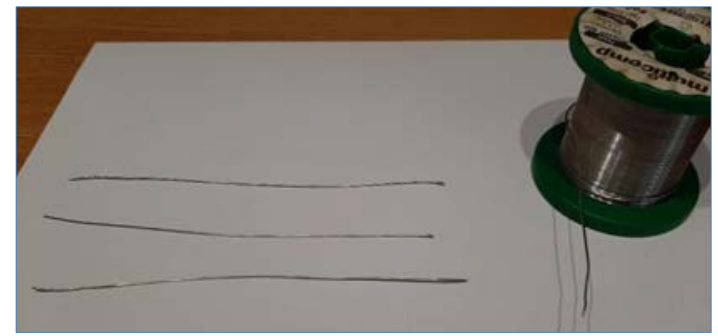

a. Specimens subjected to tensile test

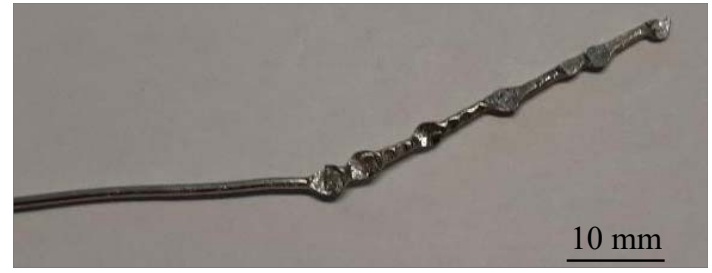

b. Extreme deformation of the specimen within the testing machine's grip

Fig. 4. Filament used as specimen for direct testing 
In figure 5 , it can be observed that the test failed and the tested filament accepted $0.001 \%$ extension until breakage due to the high deformation within the grips. The maximum supported force was $0.68 \mathrm{kN}$. Subsequently, it was decided to use thicker bars (squared bars in transverse section, $12 \mathrm{~mm}$ each square side). Figure 6 shows an example of a specimen already subjected to the tensile test.

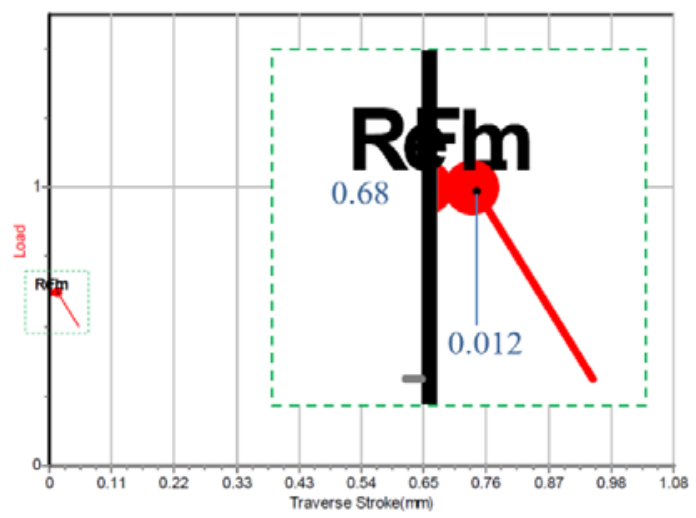

Fig. 5. Failed stress-strain curve recorded for the filament

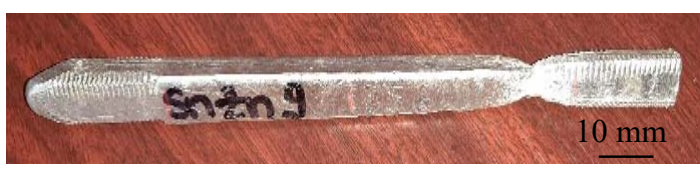

Fig. 6. Example of tensile tested specimen

A second test consisted in the real transfer of the filaments between the transfer wheels, and it was performed in order to evaluate the deformation of the filament. The wire surface and deviation from the circular shape of the section were analysed, as shown in figures 7 to 9 .

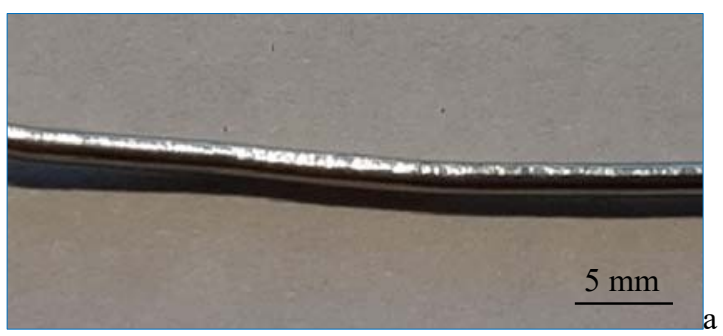

a. $\mathrm{Sn}-58 \mathrm{Bi}$

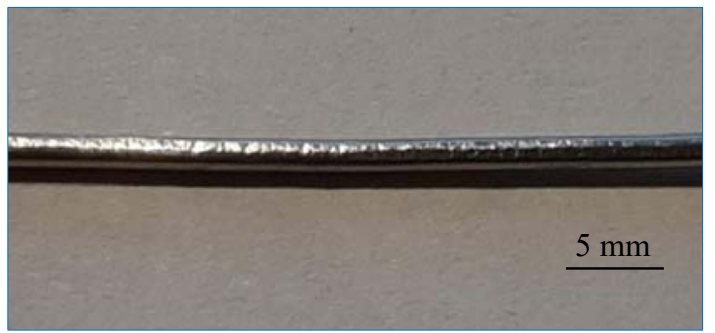

b. Sn-9Zn

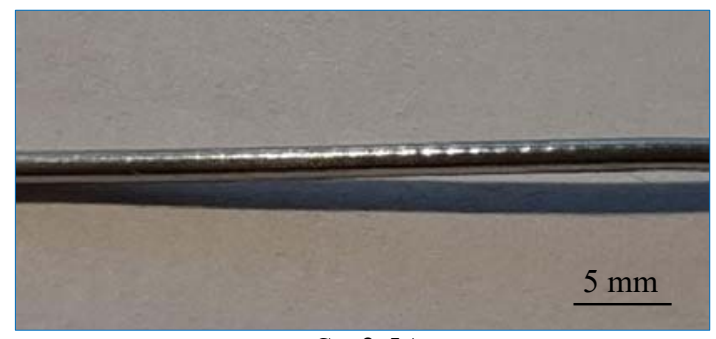

c. Sn-3.5Ag

Fig. 7. Prints on the filament

\section{RESULTS AND DISCUSSIONS}

The stress-strain curves were recorded and analysed. As it can be observed in figures 8 a to $c$ there are important differences between the mechanical behaviour of the tested materials.

According to the recorded curves, the behaviour of each tested material is characterized by a yield stress which is above $2.08 \mathrm{MPa}$. The highest yield stress belongs to $\mathrm{Sn}-58 \mathrm{Bi}$, and the recorded value was more than 25 times the effective stress inside the material, which shows that the material is able to bear the forces without distortions. The second material as value of the yield stress was $\mathrm{Sn}-9 \mathrm{Zn}$, with $32.81 \mathrm{MPa}$. The difference between the two materials consists in the distinct behaviour after reaching the yield stress point. Since the curve of Sn-58Bi starts to decrease after the yield stress, the curve of Sn-9Zn continues to rise by about $2 \mathrm{MPa}$, in conditions of plastic deformation. Moreover, the decrease of $\mathrm{Sn}-58 \mathrm{Bi}$ is slow and almost follows the same mathematical model until the breakage moment. In a different type of behaviour, Sn-Zn behaved similarly until the strain reached around $17.5 \%$. After that value, the curve dramatically changed its shape, speeding the rate of decrease.

A similar shape of the stress-strain curve was recorded for $\mathrm{Sn}-3.5 \mathrm{Ag}$, but for lower values, as it can be seen in figure $8 \mathrm{c}$. The yield strength is about $30 \%$ lower as compared to the value recorded for $\mathrm{Sn}-9 \mathrm{Zn}$, but it is still more than 10 times the calculated value of the stress.

The recorded values prove that any of the three materials tested is able to react appropriately to the transfer forces. An important piece of information given by the recorded curves is the extension of the specimens during the test. The extension is a measure of their elasticity, being an influence factor that is used to calculate the Young's modulus of the materials. The curves from figures $8 \mathrm{a}, \mathrm{b}$ and $\mathrm{c}$ show increasing angles of the elastic domains of the curves, from $\mathrm{Sn}-58 \mathrm{Bi}$ to $\mathrm{Sn}-3.5 \mathrm{Ag}$.

The elastic domains of the curves show elastic modulus values of about $53 \mathrm{GPa}$ for $\mathrm{Sn}-58 \mathrm{Bi}, 61 \mathrm{GPa}$ for $\mathrm{Sn}-9 \mathrm{Zn}$, and $51 \mathrm{GPa}$ for $\mathrm{Sn}-3.5 \mathrm{Ag}$. A foreseen problem is related to the low values of the measured extensions $(1.72 \%$ for $\mathrm{Sn}-58 \mathrm{Bi}, 4.12 \%$ for $\mathrm{Sn}-9 \mathrm{Zn}$, and $8.78 \%$ for $\mathrm{Sn}-3.5 \mathrm{Ag})$. 


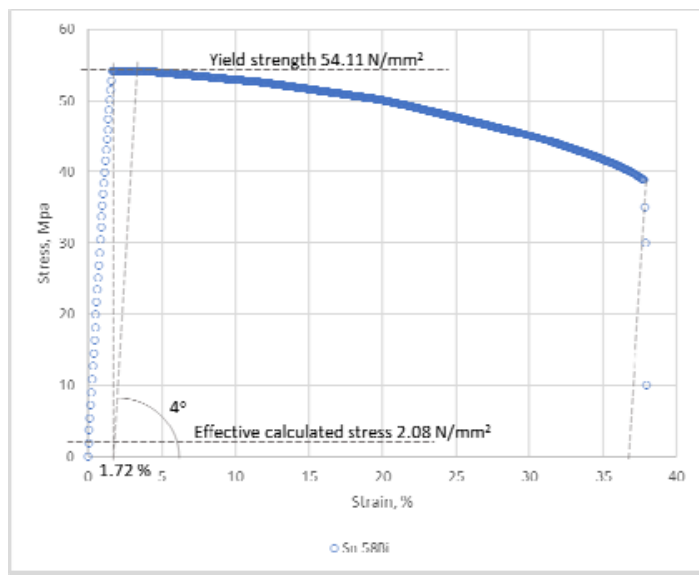

a. $\mathrm{Sn}-58 \mathrm{Bi}$

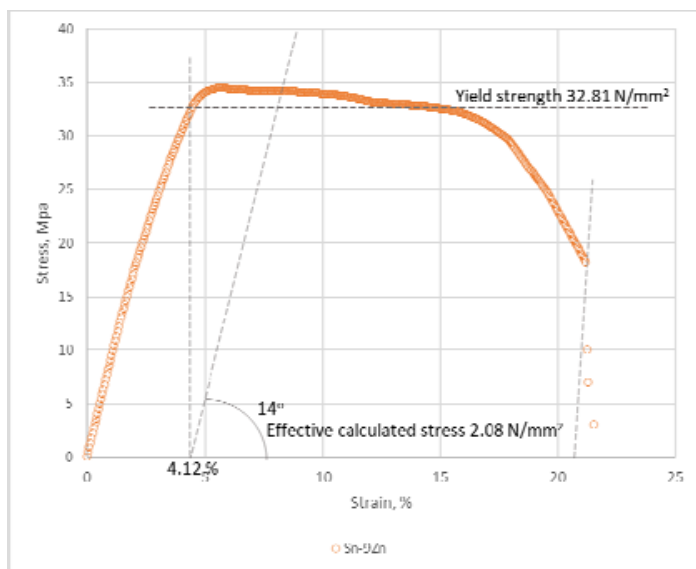

b. Sn-9Zn

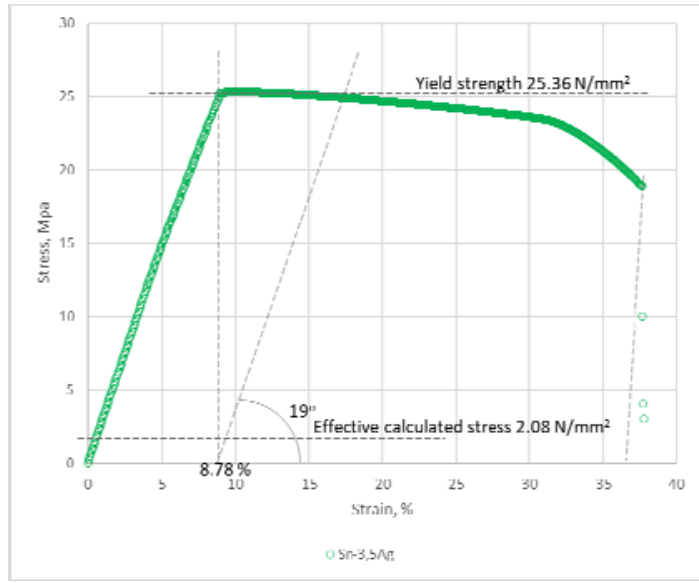

c. $\mathrm{Sn}-3.5 \mathrm{Ag}$

Fig. 8. Stress-strain curves recorded during the tensile tests

If the stress will accidentally undergo a fast increase, the low values are considered as risks. The problem is limited by the high yield stress, which proved to be more than 10 times the value of the effective stress. In this complex case, it is expected to have deformation of the filament that is low enough not to disturb the transfer process.

The analysis of the surface showed that the specific prints are marked by the wheels on the surface of the filaments. The depth of the prints decreased with the increase of the yield stress of the tested materials. The deepest prints were recorded for the Sn-3.5Ag alloy, and the measurements revealed that the maximum values are $100 \mu \mathrm{m}$ for $\mathrm{Sn}-3.5 \mathrm{Ag}$. The prints for $\mathrm{Sn}-9 \mathrm{Zn}$ and $\mathrm{Sn}-58 \mathrm{Bi}$ were measured by means of a profilometer and it was found that they were below $50 \mu \mathrm{m}$ (Fig. 9).

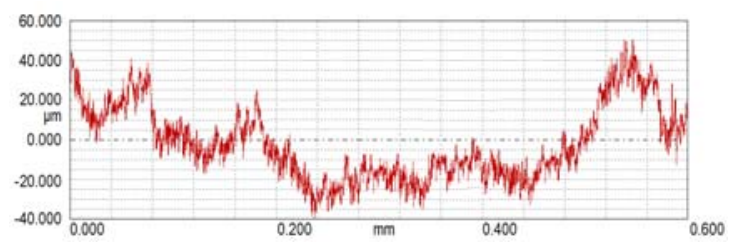

Fig. 9. Profilometer graph of the prints for $\mathrm{Sn}-9 \mathrm{Zn}$ filament

\section{CONCLUSIONS}

Fusion Deposition Modelling printing process uses polymer filaments for deposition. The filament is melted at temperatures from $180^{\circ} \mathrm{C}$ to $280^{\circ} \mathrm{C}$ during the process and the molten polymer is deposited layer over layer to obtain shapes. There is no research on the replacement of polymers with metals in the FDM process. The reason is the low temperature developed by the printer.

Based on calculus, the polymer filament is subjected to forces of around $5 \mathrm{~N}$, i.e., a stress level of max $2 \mathrm{MPa}$ developed inside the material. After two tests applied to three chosen low fusion metals (eutectic or near-eutectics for solders), it was revealed that their yield stresses are at least 10 times the effective stress inside the material. The surface of the filaments underwent deformations due to the transfer wheels and the deformations appear like prints given by the profile of the wheels.

In is considered that each of the three materials, $\mathrm{Sn}-58 \mathrm{Bi}$, and $\mathrm{Sn}-9 \mathrm{Zn}$, and $\mathrm{Sn}-3.5 \mathrm{Ag}$, provide an appropriate response when functioning as filaments. According to the applied tests, the best behaviour was seen in $\mathrm{Sn}-58 \mathrm{Bi}$, but its price is high enough to make Sn-9Zn be accepted instead.

\section{REFERENCES}

[1] Shahrubudin N., Lee T. C., Ramlan R., An Overview on $3 D$ Printing Technology: Technological, Materials, and Applications, Procedia Manufacturing 35 (2019) 1286-1296.

[2] Ciornei, M., 3D printing for rapid prototyping and fabrication - economic aspects, $11^{\text {th }}$ iCOnEc Conference, Craiova, Ro, 25-26.10.2019.

[3] Rusu C., Belaid S., Mistodie L., Adjerid S., ConditionBased Maintenance Model for the Optimization of Smart Manufacturing Processes, Annals of "Dunarea de Jos" University 
of Galati, Fascicle XII, Welding Equipment and Technology, vol. 30, 2019, pp. 34-42. DOI: https://doi.org/10.35219/awet.2019.05.

[4] Savu R., Ciornei M., Suntem pregătititi pentru Industria 4.0? Dar pentru Societatea 5.0? National Conference of the Labour Inspectorates, Brașov, 2019.

[5] Berger A., Sharon Y., Ashkenazi D., Stern A., Test artifact for additive manufacturing technology: FDM and SLM preliminary results, The Annals of "Dunarea De Jos" University of Galati Fascicle XII, Welding Equipment and Technology, vol. 27, 2016, pp. 29-37.

[6] Finnes T., High Definition 3D Printing - Comparing SLA and FDM Printing Technologies, The Journal of Undergraduate Research: Vol. 13, Article 3, 2015, available at: http://openprairie.sdstate.edu/jur/vol13/iss1/3

[7] Savu I. D., Savu S. V., Simion D., Sirbu A. N., Ciornei M., Ratiu. S. A., PP in 3D Printing - Technical and Economic Aspects, Materiale Plastice, 56, no. 4, 2019, pp 931-936.

[8] Melnikova R., Ehrmann A., Finsterbusch K., 3D printing of textile-based structures by Fused Deposition Modelling (FDM) with different polymer materials, Published under licence by IOP Publishing Ltd, IOP Conference Series: Materials Science and Engineering, vol. 62, conference 1.

[9] Mahamood R., Akinlabi S., Shatalov M., Murashkin E. Akinlabi E., Additive Manufacturing / 3D Printing Technology: A Review, Annals of "Dunarea de Jos" University of Galati, Fascicle XII, Welding Equipment and Technology, vol. 30, 2019, pp. 51-58, DOI: https://doi.org/10.35219/awet.2019.07.

[10] Turner B. N., Strong R., Gold S. A., A review of melt extrusion additive manufacturing processes: I. Process design and modeling, Rapid Prototyping Journal 20.3, 2014, pp. 192-204.

[11] Durgun I., Ertan R., Experimental investigation of FDM process for improvement of mechanical properties and production cost, Rapid Prototyping Journal 20.3, 2014, pp. 228-235

[12] Shabat D., Rosenthal Y., Ashkenazi D., Stern A., Mechanical and structural characteristics of fused deposition modelling ABS material, Annals of "Dunarea de Jos" University of
Galati, Fascicle XII, Welding Equipment and Technology, vol. 28, 2017, pp.16-24.

[13] Li G., Zhao J., Wu W., Jiang J., Wang B., Jiang H., Fuh J.Y.H., Effect of ultrasonic vibration on mechanical properties of $3 D$ printing non-crystalline and semi-crystalline polymers, Materials 11.5 , 2018, pp. 826-839.

[14] Rosenthal, Y., Stern, A., Treivish, I. and Ashkenazi, D. Crack Propagation in Flexural Testing of Additive Manufactured Acrylonitrile Butadiene Styrene, Annals of "Dunarea de Jos" University of Galati, Fascicle XII, Welding Equipment and Technology, vol. 30, 2019, pp. 21-26.

DOI: https://doi.org/https://doi.org/10.35219/awet.2019.03.

[15] Go J., Hart A. J., A framework for teaching the fundamentals of additive manufacturing and enabling rapid innovation, Additive Manufacturing. vol. 10, 2016, pp. 76-87.

[16] Savu S. V., Savu I. D., Influence of the ultrasonic activation on the wetting process and on the Ag3Sn needles evolution in the soldering process of copper by using Sn-Ag3.5\% solder, U.P.B. Sci. Bull., Series B, vol. 81, iss. 2, 2019, ISSN 1454-2331, pp. 155-170.

[17] Savu S. V., Savu I. D., Intermetallic behaviour in ultrasonic activation of the $\mathrm{Sn}-\mathrm{Ag}$ - $\mathrm{Cu}$ solder during eutectic soldering process, U.P.B. Sci. Bull., Series B, vol. 80, iss., 2, 2018 , ISSN 1454-2331, pp. 193-212.

[18] Siviour C., Walley S. M., Proud W., Field J., Mechanical properties of $\mathrm{SnPb}$ and lead-free solders at high rates of strain. Journal of Physics D: Applied Physics. 38, 4131 https://doi.org/10.1088/0022-3727/38/22/018. 2005.

[19] Roh M. H., Jung J. P., Kim W., Microstructure, shear strength, and nanoindentation property of electroplated $S n-B i$ micro-bumps, Microelectronics Reliability, vol. 54, no. 1, 2014, pp. 265-271.

[20] Madeni J. C., Liu S., Effect of thermal aging on the interfacial reactions of tin-based solder alloys and copper substrates and kinetics of formation and growth of intermetallic compounds, Soldag. insp. (Impr.) vol. 16, no.1 São Paulo Jan./Mar. 2011, https://doi.org/10.1590/S0104-92242011000100011. 